\title{
IRG1 induced by heme oxygenase-1/carbon monoxide inhibits LPS-mediated sepsis and pro-inflammatory cytokine production
}

\author{
Md Jamal Uddin ${ }^{1}$, Yeonsoo Joe ${ }^{1}$, Seul-Ki Kim ${ }^{1}$, Sun Oh Jeong ${ }^{2}$, Stefan W Ryter ${ }^{3}$, Hyun-Ock Pae ${ }^{2}$ \\ and Hun Taeg Chung ${ }^{1}$
}

The immunoresponsive gene 1 (IRG1) protein has crucial functions in embryonic implantation and neurodegeneration. IRG1 promotes endotoxin tolerance by increasing A20 expression in macrophages through reactive oxygen species (ROS). The cytoprotective protein heme oxygenase-1 (HO-1), which generates endogenous carbon monoxide (CO), is expressed in the lung during Lipopolysaccharide (LPS) tolerance and cross tolerance. However, the detailed molecular mechanisms and functional links between IRG1 and HO-1 in the innate immune system remain unknown. In the present study, we found that the $\mathrm{CO}$ releasing molecule-2 (CORM-2) and chemical inducers of HO-1 increased IRG 1 expression in a time- and dose-dependent fashion in RAW264.7 cells. Furthermore, inhibition of HO-1 activity by zinc protoporphyrin IX (ZnPP) and HO-1 siRNA significantly reduced expression of IRG1 under these conditions. In addition, treatment with $\mathrm{CO}$ and HO-1 induction significantly increased A2O expression, which was reversed by ZnPP and HO-1 siRNA.

LPS-stimulated TNF- $\alpha$ was significantly decreased, whereas IRG 1 and A20 were increased by CORM-2 application and HO-1 induction, which in turn were abrogated by ZnPP. Interestingly, siRNA against IRG 1 and A20 reversed the effects of $\mathrm{CO}$ and HO- 1 on LPS-stimulated TNF- $\alpha$ production. Additionally, $\mathrm{CO}$ and HO-1 inducers significantly increased IRG 1 and A20 expression and downregulated TNF- $\alpha$ production in a LPS-stimulated sepsis mice model. Furthermore, the effects of $\mathrm{CO}$ and $\mathrm{HO}-1$ on TNF- $\alpha$ production were significantly reversed when ZnPP was administered. In conclusion, $\mathrm{CO}$ and $\mathrm{HO}-1$ induction regulates IRG1 and A20 expression, leading to inhibition of inflammation in vitro and in an in vivo mice model. Cellular \& Molecular Immunology (2016) 13,170-179; doi:10.1038/cmi.2015.02; published online 2 February 2015

Keywords: A20; anti-inflammatory effects; carbon monoxide; HO-1; IRG1

\section{INTRODUCTION}

Sepsis is a systemic inflammatory response to microbial infection. During sepsis, excessive activation of the innate immune response as the result of bacteremia or hyper-inflammation may cause organ dysfunction and death. ${ }^{1,2}$ During inflammation, pro-inflammatory cytokines and reactive oxygen species (ROS) responsible for antimicrobial activity are produced by activated peripheral macrophages, microglial cells and the resident immune cells of the central nervous system. ${ }^{3}$ However, during endotoxintolerance, a hypo-inflammatory state of the innate immune system can also result in secondary infections with organisms not typically pathogenic in the immunocompetent host. ${ }^{1}$
The immunoresponsive gene 1 (IRG1), of which protein is known as cis-aconitate decarboxylase (CAD) in human, was first recognized as a 2.3-kb cDNA from a murine macrophage cell line stimulated with lipopolysaccharide (LPS). ${ }^{4}$ Gene expression profiling studies of murine macrophages and microglial cells have revealed that IRG1 is highly expressed under pro-inflammatory conditions. ${ }^{5,6}$ Avian spleen macrophages displayed significantly increased expression of IRG1 after Salmonella enterica infection. ${ }^{7}$ Furthermore, IRG1 is highly expressed in the pregnant uterus during the early events leading to implantation, ${ }^{8}$ the specific phase of pregnancy in which high levels of inflammatory cytokines are secreted. ${ }^{9}$

${ }^{1}$ School of Biological Sciences, University of Ulsan, Korea; ${ }^{2}$ Department of Microbiology and Immunology, Wonkwang University School of Medicine, Korea and ${ }^{3}$ Joan and Sanford I. Weill Department of Medicine, New York-Presbyterian Hospital, Weill Cornell Medical College, New York, USA

Correspondence: Dr HT Chung, School of Biological Sciences, University of Ulsan, Korea.

E-mail: chung@ulsan.ac.kr

Dr HO Pae, Department of Microbiology and Immunology, Wonkwang University School of Medicine, Korea.

E-mail: hopae@wku.ac.kr

Received: 22 September 2014; Revised: 3 January 2015; Accepted: 3 January 2015 
IRG1 expression is also deregulated in autoimmune or inflammatory diseases. ${ }^{6}$ Furthermore, IRG1 localizes to the mitochondria and may represent a key link between immunological and metabolic processes. ${ }^{6}$ IRG1 has crucial functions in embryonic implantation and neurodegeneration. ${ }^{10}$ Also, IRG1 promotes endotoxin tolerance by increasing A20 expression in macrophages via increased ROS production. ${ }^{11}$ In addition, knockdown of IRG1 increased the activation of NF- $\mathrm{KB}$ and IRF3, which was accompanied by decreased A20 expression and ROS production. Despite these observations, the precise molecular and biological functions of IRG1 in the innate immune response remain unknown.

Heme oxygenase-1 (HO-1), a stress-inducible protein, catalyzes the oxidative degradation of heme to generate carbon monoxide (CO), iron and biliverdin-IX $\alpha$; and promotes cellular protection. ${ }^{12}$ In addition, anti-inflammatory, anti-apoptotic and cytoprotective properties of $\mathrm{CO}$ have been described. ${ }^{13}$ The antiinflammatory effects of HO-1 may have therapeutic potential in inflammatory conditions such as arthritis ${ }^{14}$ and inflammatory bowel disease. ${ }^{15}$ In sepsis, HO-1 is involved in the induction of IL-10 and the suppression of pro-inflammatory factors such as TNF- $\alpha$ and nitric oxide synthase- 2 in macrophages, ${ }^{16}$ and also mediates the anti-inflammatory effects of adiponectin in Kupffer cells. ${ }^{17}$ Furthermore, increased HO-1 expression was observed in the lung during LPS tolerance and cross tolerance. ${ }^{18}$ In addition, overexpression of hepatic $\mathrm{HO}-1$ has been observed during endotoxin tolerance. ${ }^{19}$ Currently, there are no reports regarding the effects of HO-1 on the regulation of IRG1 expression under proinflammatory conditions.

Since both HO-1 and IRG1 proteins are simultaneously expressed during endotoxin tolerance and regulate anti-inflammatory functions, we examined the functional link between HO-1 and IRG1 expression with respect to inhibition of inflammation in a murine model in vivo and in vitro.

\section{METHODS AND MATERIALS}

\section{Reagents and antibodies}

Antibodies against HO-1 and A20 were purchased from Cell Signaling Technology (Danvers, MA, USA). Antibodies against IRG1, $\beta$-actin and anti-mouse and anti-goat antibodies conjugated to horseradish peroxidase were obtained from Santa Cruz Biotechnology (Santa Cruz, CA, USA). CO-releasing molecule-2 (CORM-2, tricarbonyl dichlororuthenium dimer), ruthenium chloride $\left(\mathrm{RuCl}_{3}\right)$, LPS, cobalt protoporphyrin IX (CoPP), hemin and protease inhibitor cocktail sets were purchased from Sigma-Aldrich (St Louis, MO, USA). Zinc protoporphyrin IX (ZnPP) was from Frontier Scientific Inc. (Logan, UT, USA). Dulbecco's modified Eagle medium, fetal bovine serum, penicillin-streptomycin and sodium pyruvate were purchased from Invitrogen (Grand Island, NY, USA). All other chemicals were obtained from Sigma-Aldrich.

\section{Cell culture}

RAW264.7 cells were cultured in Dulbecco's modified Eagle medium with $10 \%$ heat-inactivated fetal bovine serum and $1 \%$ penicillin-streptomycin at $37{ }^{\circ} \mathrm{C}$ in $5 \% \mathrm{CO}_{2}$. Cells were cultured to $75 \%-80 \%$ confluence and then split at a density of $5 \times 10^{5}$ cells $/ \mathrm{ml}$ in six-well plates. The cells were incubated overnight and then treated with or without LPS (100 ng/ml) for $8 \mathrm{~h}, 16 \mathrm{~h}$ or $24 \mathrm{~h}$. After incubation, cells were harvested for reverse transcription-polymerase chain reaction (RT-PCR), real-time RT-PCR and western blotting. Cell supernatants were collected for ELISA assays (R\&D Systems, Inc., Minneapolis, MN, USA) for measuring the level of TNF- $\alpha$ production.

\section{Animal model of endotoxemia}

Seven-week-old male C57BL/6 wild-type mice were exposed to inhalation of CO gas (250 ppm) $4 \mathrm{~h} /$ day for 6 days or treated with CORM-2 (30 mg/kg, i.p.) and hemin $(10 \mathrm{mg} / \mathrm{kg}$, i.p.) for $2 \mathrm{~h}$; with or without $\mathrm{ZnPP}$ ( $5 \mathrm{mg} / \mathrm{kg}$, i.p.), respectively (Tsoyi et al., 2011). After $2 \mathrm{~h}$ or 6 days, the mice were injected with LPS $(12.5 \mathrm{mg} / \mathrm{kg}$, i.p.) to induce endotoxemia. At $16 \mathrm{~h}$ post-injection, mice were sacrificed, and blood serum and liver tissues were collected and stored at $-80{ }^{\circ} \mathrm{C}$ for protein and RNA analysis. All experiments with mice were approved by the Animal Care Committee of the University of Ulsan, Ulsan, Korea.

\section{Transfection}

Predesigned siRNAs were purchased from Santa Cruz Biotechnology. RAW264.7 cells $\left(5 \times 10^{5} / \mathrm{ml}\right)$ were cultured in sixwell plates for $3 \mathrm{~h}$ and then transfected with IRG1 siRNA $(100 \mathrm{nM})$ or A20 siRNA $(100 \mathrm{nM})$ or HO-1 siRNA (100 nM), using lipofectamine 2000 according to the manufacturer's instructions. After transfection, cells were treated with CORM$2(20 \mu \mathrm{M})$ or hemin $(10 \mu \mathrm{M})$ with or without LPS $(100 \mathrm{ng} / \mathrm{ml})$.

\section{Western blotting}

After harvesting of the cells, protein extracts were prepared using lysis buffer containing RIPA buffer, with protease and phosphatase inhibitors. Protein concentration in the cell lysate was measured by the bicinchoninic protein assay (Pierce Biotechnology Inc., Rockford, IL, USA). An equal amount of protein for all samples was subjected to electrophoresis and then transferred to polyvinylidene difluoride membranes. The membranes were blocked with $5 \%$ non-fat milk in PBS containing $0.1 \%$ Tween 20 for $20 \mathrm{~min}$ and incubated at $4{ }^{\circ} \mathrm{C}$ overnight with primary antibodies for HO-1, IRG1, A20 and $\beta$ actin, followed by secondary antibodies conjugated with horseradish peroxidase. Immunocomplexes were visualized using the enhanced chemiluminescence western blotting detection system (GE Healthcare Life Sciences, Buckinghamshire, UK).

\section{RT-PCR}

Total RNA was extracted using the TRIzol reagent (Invitrogen, CA, USA) according to the manufacturer's instructions. In short, $2 \mu \mathrm{g}$ of total RNA was used to make cDNA by using M-MLV reverse transcriptase (Promega Corporation, WI, USA) and oligo (dT) 15 primer (Promega Corporation, Madison, WI, USA). The resulting cDNA was subjected to PCR for mouse GAPDH (forward (f)-aggccggtgctgagtatgtc, reverse (r)-tgcctgcttcaccttct, $530 \mathrm{bp}$ ), HO-1 (f-tcccagacaccgc- 
tcctccag, r-ggatttggggctggtttc, 313 bp), IRG1 (f-ggtatcattcggaggagaa, $r$-acagagggagggtggaatct, $440 \mathrm{bp}$ ) and TNF- $\alpha$ (f-agcccacgtcgtagcaaaccaccaa, $r$-acacccattcccttcacagagcaat, $421 \mathrm{bp}$ ). PCR was performed with the following conditions: denaturation temperature $94{ }^{\circ} \mathrm{C}$ for $0.5 \mathrm{~min}$, annealing temperature (according to respective primer) for $0.5 \mathrm{~min}$ and extension temperature $72{ }^{\circ} \mathrm{C}$ for $1 \mathrm{~min}$, and the PCR cycle was determined according to a kinetic profile. GAPDH was used as an internal loading control. PCR products were observed on $2 \%$ agarose gels containing ethidium bromide using a digital gel documentation set.

\section{Real-time RT-PCR}

Total RNA was extracted from RAW264.7 cells or mouse liver tissues using the TRIzol reagent (Invitrogen, Carlsbad CA, USA) according to the manufacturer's instructions. In brief, $2 \mu \mathrm{g}$ of total RNA was used to make cDNA by using M-MLV reverse transcriptase (Promega Corporation, Madison, WI, USA) and oligo (dT) 15 primer (Promega Corporation, Madison, WI, USA). The resulted CDNA was subjected to real-time RT-PCR using SYBR Green qPCR Master Mix (Applied Biosystem Warrington, WA1, UK) on an ABI 7500 Fast Real-Time PCR System (Applied Biosystem Warrington, WA1, UK) for mouse GAPDH (f-gggaagcccatcaccatct, r-cggcctfcaccccatttg), IRG1 (fgctgtgcaggtgttgagcc, r-cataactgtgttcccgaggtgtc), A20 (f-gcctgtgcaaaagagatttcagat, r-tgattcacagagcatgtaggcc), HO-1 (f-tcagtcccaaacctcgcggt, $r$-gctgtgcaggtgttgagcc) and TNF- $\alpha$ (f-agaccctcacactcagatca, r-ttgctacgacgtgggctaca). GAPDH was used as an internal loading control to normalize all PCR products.

\section{Enzyme-linked immunosorbent assay (ELISA)}

RAW264.7 macrophages on six-well plates were incubated overnight and then pre-treated with CORM-2 or hemin with or without ZnPP for $30 \mathrm{~min}$ followed by stimulation with LPS for $24 \mathrm{~h}$. In addition, mice were administrated with $\mathrm{CO}$ gas or CORM-2 or hemin with or without $\mathrm{ZnPP}$ for $2 \mathrm{~h}$ and sepsis was induced by LPS injection. The TNF- $\alpha$ levels of supernatant collected from different samples or blood serum collected from different mice were assayed by using mouse ELISA kit (R\&D systems, Minneapolis, MN, USA).

\section{Statistical analysis}

Results are expressed as the means \pm s.d. Statistical differences between groups were evaluated by one-way ANOVA or Student's $t$-test when multiple groups were compared. Differences were considered to be significant when $P<0.05$.

\section{RESULTS}

\section{$\mathrm{CO}$ and HO-1 induction increases IRG1 expression in macrophages}

$\mathrm{CO}$ is produced as an end product of $\mathrm{HO}-1$ activity. CO-releasing molecules (i.e., CORM-2) can release $\mathrm{CO}$ in a controllable manner under physiological conditions. ${ }^{20}$ IRG1, which is highly conserved in vertebrates, exerts crucial functions during the immune response, ${ }^{4}$ whereas $\mathrm{HO}-1$, a stress-inducible enzyme, can confer protection in inflammation. Both HO- $1^{19}$ and IRG1 ${ }^{11}$ were found to be increased during endotoxin tol- erance, suggesting a potential regulatory link between HO-1 and IRG1. To examine this hypothesis, we treated the murine macrophage cell line RAW264.7 with CORM-2 $(20 \mu \mathrm{M})$ for varying time periods. Following CORM-2 treatment, IRG1 expression increased at $16 \mathrm{~h}$, whereas $\mathrm{HO}-1$ expression began to increase at $4 \mathrm{~h}$ (Figure 1a). Therefore, in subsequent experiments, we measured IRG1 expression at $16 \mathrm{~h}$. In addition, CORM-2 treatment dose-dependently increased activity of HO-1 (Supplemenatry Figure 1c) at $16 \mathrm{~h}$, and the levels of IRG1 and HO-1 mRNA (Figure $1 \mathrm{~b}$ and Supplementary Figure $1 \mathrm{a}$ and $\mathrm{b}$ ) and protein (Figure 1c) at $8 \mathrm{~h}$ and $16 \mathrm{~h}$, respectively. CoPP is a potent and well-known inducer of HO- $1{ }^{21}$ Hemin, a constituent of hemoglobin, may have therapeutic potential for the treatment of acute porphyrias. ${ }^{22}$ The anti-inflammatory or host defense functions of hemin may be mediated via stimulation of HO-1 expression. ${ }^{23}$ We therefore examined the effects of CoPP and hemin on HO-1 and IRG1 expression. RAW264.7 cells were treated with CoPP or hemin $(0-20 \mu \mathrm{M})$. CoPP increased the levels of IRG1 and HO-1 mRNA (Figure 1d) and protein (Figure. 1e) in a dose-dependent fashion. Similarly, hemin increased IRG1 and HO-1 mRNA (Figure 1f and Supplementary Figure 1d and e) and protein (Figrue 1g) levels.

To confirm the effect of CO on HO-1 and IRG1 expression, we used $\mathrm{RuCl}_{3}$ as a negative control for CORM- 2 to rule out the effect of the ligand ruthenium of CORM-2. $\mathrm{RuCl}_{3}$ contains the metal ruthenium as ligand and the non-metal chloride as substitute group, and the ligand ruthenium of CORM-2 itself may influence HO-1 expression. $\mathrm{RuCl}_{3}(10-20 \mu \mathrm{M})$ had no effect on HO-1 and IRG1 expression (Figure 2a), confirming the involvement of CO (but not ruthenium) in the effects of CORM-2. To further confirm the effects of CO, CO gas (250 ppm) was used. We found that treatment of $\mathrm{CO}$ gas significantly increased mRNA levels of HO-1 and IRG1 in a time dependent manner (Supplementary Figure 2a). Furthermore, to evaluate the role of CORM-2-induced HO-1 on IRG1 expression, the HO-1 inhibitor $\mathrm{ZnPP}$ was used. ZnPP treatment $(10-20 \mu \mathrm{M})$ inhibited the expression of IRG1 mRNA (Figure 2b and Supplementary Figure $2 \mathrm{~b}$ ) and protein (Figure 2d and Supplementary Figure 2c) induced by CORM-2 in RAW264.7 cells with no signifi cant effect on HO-1 mRNA (Figure $2 \mathrm{c}$ and Supplementary Figure $2 \mathrm{~b}$ ). In loss function experiment of HO-1 using HO-1 siRNA, we found that HO-1 gene silencing significantly inhibited CORM-2 induced protein (Figure 2e) and mRNA (Supplementary Figure 2d) levels of IRG1. This result suggests that CO-induced HO-1 activity may regulate IRG1 expression in macrophages. In support of this hypothesis, we found that the HO-1 inducing compounds CoPP and hemin $(10 \mu \mathrm{M})$ induced IRG1 mRNA (Figure 2f and Supplementary Figure $2 \mathrm{e}$ ) and protein (Figure $2 \mathrm{~g}$ and Supplementary Figure 2f); whereas expression induced by these agents was significantly $(P<0.01)$ inhibited by $\mathrm{ZnPP}$ treatment $(20 \mu \mathrm{M})$. In addition, basal expression of IRG1 mRNA was significantly inhibited in the liver tissue from HO-1 KO mice (Supplementary Figure 2g). These data suggest that HO-1 is an upstream regulatory protein for IRG1 expression. 
a

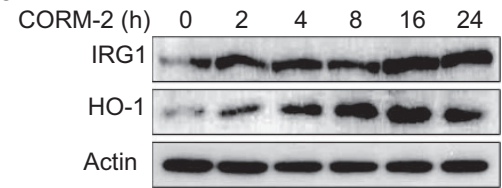

c

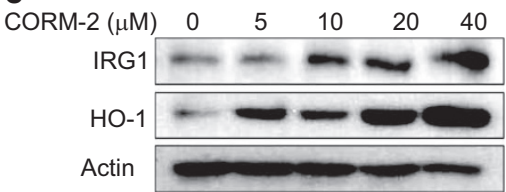

e

$\begin{array}{llllll}\operatorname{CoPP}(\mu \mathrm{M}) & 0 & 1 & 5 & 10 & 20\end{array}$

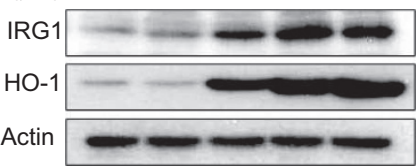

g

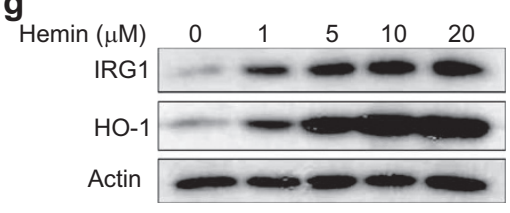

b

$\begin{array}{llllll}\text { CORM-2 }(\mu \mathrm{M}) & 0 & 5 & 10 & 20 & 40\end{array}$

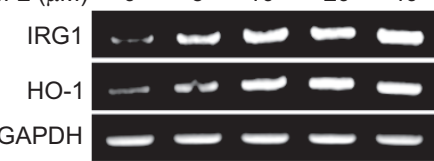

d

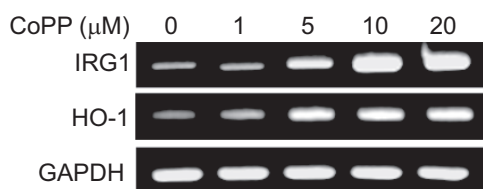

f

Hemin $(\mu \mathrm{M}) \quad 0 \quad 1 \quad 5 \quad 10 \quad 20$

$\mathrm{IRG} 1=-2$

$\mathrm{HO}-1-2-\infty$

$\mathrm{GAPDH}=-\infty$

Figure 1 CORM-2, CoPP and hemin increase IRG1 expression in RAW264.7 macrophages. (a) RAW264.7 cells were treated with $20 \mu \mathrm{M}$ CORM-2 for 0, 2 , 4, 8, 16 and $24 \mathrm{~h}$ and protein level of IRG1 and HO-1 were detected by western blot analysis. (b and c) RAW264.7 cells were treated with CORM-2 (0, 5, 10, 20 and $40 \mu \mathrm{M})$ for 8 or $16 \mathrm{~h}$. IRG1 and HO-1 mRNA and protein were measured, by RT-PCR analysis. (d-g) RAW264.7 cells were treated with CoPP or hemin $(0,1,5,10$ and $20 \mu \mathrm{M})$ for 8 or $16 \mathrm{~h}$. (d) After CoPP treatment at the indicated concentrations $(0-20 \mu \mathrm{M})$ for $8 \mathrm{~h}$, mRNA expression of IRG1 and HO-1 were detected. (e) After CoPP treatment $(0-20 \mu \mathrm{M})$ for $16 \mathrm{~h}$, IRG1 and HO-1 protein level were detected. (f) After hemin treatment at the indicated concentrations (0-20 $\mu \mathrm{M})$ for $8 \mathrm{~h}$, mRNA expression of IRG1 and HO-1 were detected. (g) After hemin treatment (0-20 $\mu \mathrm{M})$ for 16 h, IRG1 and HO-1 protein level were detected. Protein level was detected by western blot analysis and mRNA levels were measured by RT-PCR analysis. Representative bands are shown.

\section{NO increases IRG1 expression in a HO-1-dependent manner in macrophages}

The free radical gas NO can exert a variety of physiological functions, including the promotion of cell survival during conditions of serum starvation and oxidative stress. ${ }^{24,25}$ Furthermore, NO is involved in HO-1 upregulation. ${ }^{26}$ To further elucidate the involvement of HO-1 in IRG1 regulation, we used the NO donor SNAP. Treatment of RAW264.7 cells with SNAP $(0-40 \mu \mathrm{M})$ significantly increased both IRG1 and HO-1 expression (Supplementary Figure 3a and b). To further confirm the role of HO-1 in NO-dependent IRG1 expression, we pre-treated RAW264.7 cells with ZnPP $(20 \mu \mathrm{M})$ and then incubated the cells with SNAP for $8 \mathrm{~h}$ or $16 \mathrm{~h}$. ZnPP treatment significantly inhibited IRG1 mRNA and protein level induced by SNAP (Supplementary Figure $3 \mathrm{c}$ and $\mathrm{d}$ ). These data further support the regulatory link between HO-1 and IRG1 in anti-inflammatory processes.

\section{HO-1 regulates $\mathrm{A} 20$ in macrophages}

The zinc-finger protein A20 (also known as TNFAIP3) is a key negative regulator of NF- $\mathrm{\kappa B}$ signaling downstream of innate immune receptors such as tumors necrosis factor receptor and Toll-like receptors. ${ }^{27}$ Furthermore, IRG1 is known to promote endotoxin tolerance by increasing A20 expression. ${ }^{11}$ Therefore, we measured the effects of $\mathrm{CO}$ and $\mathrm{HO}-1$ on A20 regulation. CORM-2 time-dependently increased A20 protein level beginning at $16 \mathrm{~h}$ (Figure 3a). Treatment of RAW264.7 macrophages with CORM-2 also increased A20 expression in a dose-dependent manner (Figure $3 \mathrm{~b}$ and $\mathrm{c}$ ). To evaluate the effect of CORM-2-induced HO-1 on A20 expression, we pre-treated RAW264.7 macrophages with $\mathrm{ZnPP}(20 \mu \mathrm{M})$, and the cells were incubated with CORM-2. Interestingly, ZnPP $(20 \mu \mathrm{M})$ pre-treatment reduced A20 mRNA (Figure 3d) and protein (Figure 3e and Supplementary Figure 4a) expression in response to CORM-2 stimulation. In loss function experiment using HO-1 siRNA, we found that HO-1 gene silencing dramatically diminished CORM-2 induced protein levels of A20 (Figure 2f). In addition, to confirm the direct effect of HO-1 on A20 expression, macrophages were treated with hemin, which caused increased A20 expression (Figure 3g and 3h). ZnPP pretreatment $(20 \mu \mathrm{M})$, significantly decreased A20 protein level in response to hemin (Figure $3 \mathrm{~h}$ and Supplementary Figure $4 \mathrm{~b}$ ), suggesting a role for HO-1 in A20 regulation.

\section{$\mathrm{CO}$ and HO-1 mediated IRG1 expression decreases inflammation via A20 expression in macrophages}

A20 is widely known to regulate inflammation and immunity, and confers cellular protection from TNF- $\alpha$-induced cytotoxicity. ${ }^{28}$ 
a
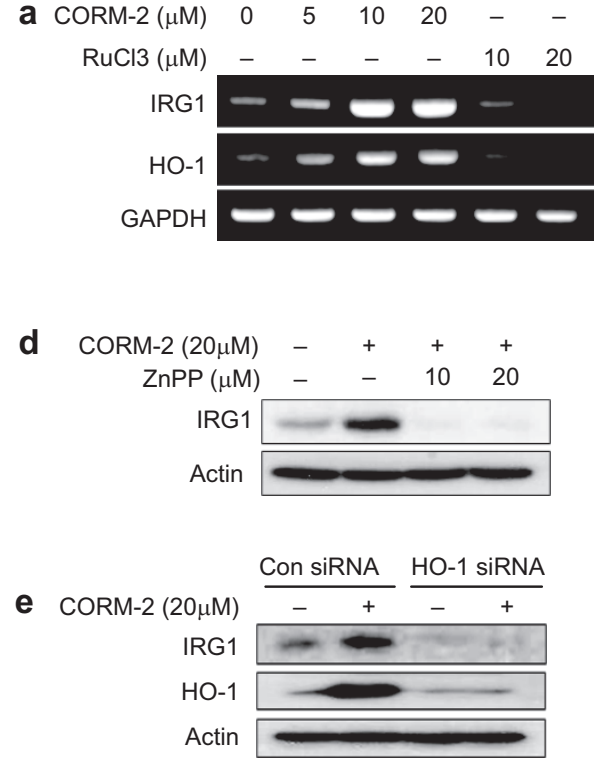

b

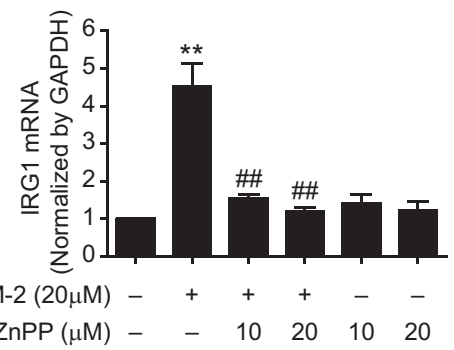

f

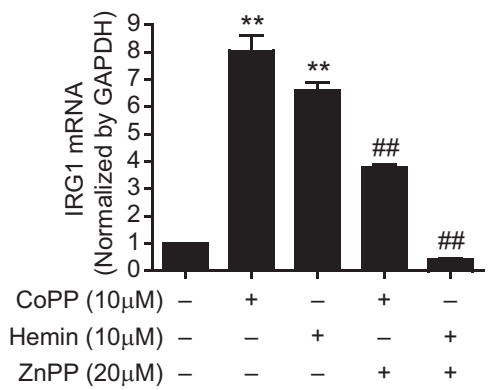

c

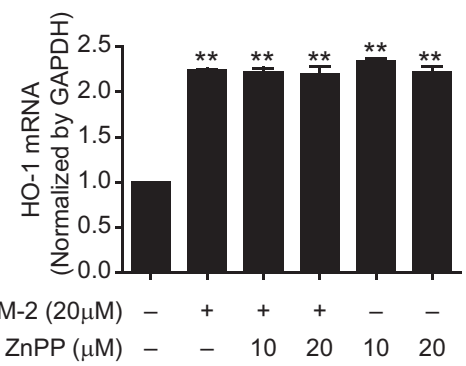

g

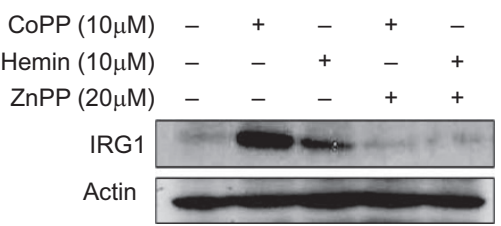

Figure 2 CORM-2 and CoPP/hemin-induced expression of IRG1 is dependent on HO-1 in RAW264.7 macrophages. (a) RAW264.7 cells were treated with CORM-2 $(0,5,10$ and $20 \mu \mathrm{M})$ or its negative control, $\mathrm{RuCl}_{3}(10$ and $20 \mu \mathrm{M})$ for $8 \mathrm{~h}$ and the levels of IRG1 and HO-1 mRNA were detected by using RT-PCR analysis. (b-d) Cells were pre-treated with ZnPP (10 and $20 \mu \mathrm{M})$ for $0.5 \mathrm{~h}$ and treated with CORM-2 for 8 or $16 \mathrm{~h}$. The levels of IRG1 (b) and HO-1 (c) mRNA were measured at $8 \mathrm{~h}$ by real-time RT-PCR and (d) IRG1 protein levels were determined at $16 \mathrm{~h}$ by western blot analysis. (e) Cells were transfected with HO-1 siRNA or control siRNA (Con siRNA). After treatment with $20 \mu \mathrm{M}$ CORM-2 for $16 \mathrm{~h}$, cells were harvested and protein levels of HO-1 and IRG1 were performed by western blotting. ( $\mathbf{f}$ and $\mathbf{g}$ ) Cells were pre-treated with $\mathrm{ZnPP}(20 \mu \mathrm{M})$ for $0.5 \mathrm{~h}$ and treated with CoPP $(10 \mu \mathrm{M})$ and hemin $(10 \mu \mathrm{M})$ for 8 or $16 \mathrm{~h}$. (f) IRG1 mRNA was measured at $8 \mathrm{~h}$ by real-time RT-PCR and (g) IRG1 protein levels were determined at $16 \mathrm{~h}$ by western blot analysis. The representative bands or blots are shown. Data represent mean \pm s.e.m., $* P<0.05$ and $* * P<0.001$ as compared with control and ${ }^{\# \#} P<0.001$ as compared with the cells exposed to only CORM-2, hemin or CoPP.

RAW264.7 macrophages were pre-treated with CORM-2 or hemin in the presence of $\mathrm{ZnPP}$ and then stimulated with LPS for $24 \mathrm{~h}$. CORM-2 or hemin treatment induced the upregulation of IRG1 and $\mathrm{A} 20$ protein (Figure $4 \mathrm{~b}$ and $\mathrm{f}$ ) and mRNA (Supplementary Figure 5) which were dramatically inhibited by ZnPP. Additionally, CORM-2 or hemin treatment significantly decreased LPS-induced TNF- $\alpha$ protein (Figure $4 \mathrm{a}$ and e) and mRNA (Supplementary Figure 5), and this effect was abrogated by ZnPP treatment. These results indicate a role of IRG1 and A20 expression induced by $\mathrm{CO} / \mathrm{HO}-1$ in the inhibition of inflammation. To confirm the function of IRG1 expression by $\mathrm{CO} / \mathrm{HO}-1$ in terms of inflammation regulation by $\mathrm{A} 20$, macrophages were transfected with IRG1 siRNA and treated with CORM-2 or hemin and stimulated with LPS. We found that CORM-2 or hemin-induced A20 expression was significantly downregulated whereas TNF- $\alpha$ mRNA was significantly increased by IRG1 siRNA transfection compared to control siRNA transfection (Figure $4 \mathrm{c}$ and g). Furthermore, when cells were transfected with A20 siRNA, we detected increased expression of TNF- $\alpha$ in LPS-stimulated cells while CORM-2 or hemin treatment did not reverse TNF- $\alpha$ production (Figure $4 \mathrm{~d}$ and $\mathrm{h}$ ). Based on these results, we conclude that $\mathrm{CO}$ and $\mathrm{HO}-1$ mediates anti-inflammatory effects through the IRG1-A20 axis.

\section{CO and HO-1 inhibits inflammation via IRG1 and A20 expression in an in vivo mouse model}

HO-1 was reported to improve animal survival in lethal endotoxemia. ${ }^{29,30}$ Furthermore, HO- $1,{ }^{18}$ IRG1 and A20 ${ }^{11}$ were found to be expressed under conditions of endotoxin tolerance. We also demonstrated that IRG1 and A20 increased in endotoxin tolerance (Supplementary Figure $6 \mathrm{~b}-\mathrm{d}$ ) where TNF- $\alpha$ was decreased (Supplementary Figure $6 \mathrm{a}, \mathrm{b}$ and $\mathrm{d}$ ). However, no reports have previously examined the effects of $\mathrm{HO}-1$ in relation to the regulation of IRG1 and A20 expression in the septic mouse model. In our study, we investigated the effect of $\mathrm{CO} /$ HO-1-induced IRG1 and A20 expression on LPS-induced TNF$\alpha$ production as an indicator of lethal endotoxemia. To examine the in vivo effects of CO on LPS-induced endotoxemia and expression of IRG1 and A20, mice were subjected to inhalation CO (250 ppm) for $4 \mathrm{~h}$ /day for 6 days in the absence or presence of ZnPP ( $5 \mathrm{mg} / \mathrm{kg}$, i.p.) on a daily basis for 6 days and then LPS was injected $(12.5 \mathrm{mg} / \mathrm{kg}$, i.p.). At $16 \mathrm{~h}$ post LPS injection, CO inhalation significantly decreased LPS-induced TNF- $\alpha$ levels in blood serum (Figure 5a) and liver tissues (Figure 5b) of endotoxemic mice, which were reversed by $\mathrm{ZnPP}$ treatment. In addition, CO inhalation significantly increased IRG1 and A20 mRNA levels in liver tissues, which were reversed by $\mathrm{ZnPP}$ treatment (Figure 5c). Furthermore, to confirm the effects of $\mathrm{CO}$ and HO-1 on LPS-induced endotoxemia, we pre-treated mice with CORM-2 (30 mg/kg, i.p.), hemin (10 mg/kg, i.p.) and ZnPP ( $5 \mathrm{mg} / \mathrm{kg}$, i.p.) for $2 \mathrm{~h}$, and then the mice were administrated with LPS (12.5 mg/kg, i.p.) for $16 \mathrm{~h}$. Interestingly, treatment with CORM-2 or hemin significantly increased the expression of HO-1, IRG1 and A20 mRNA (Figure 5f), and simultaneously decreased the levels of TNF- $\alpha$ protein (Figure $5 \mathrm{~d}$ ) and mRNA 
a

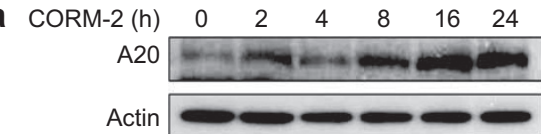

b

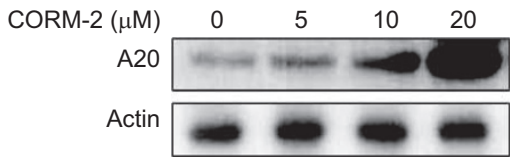

e

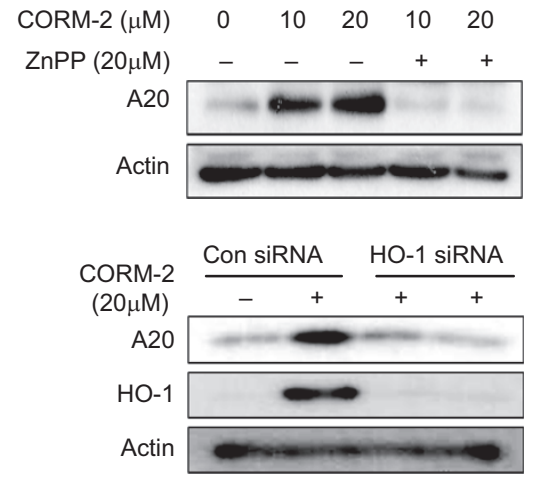

C

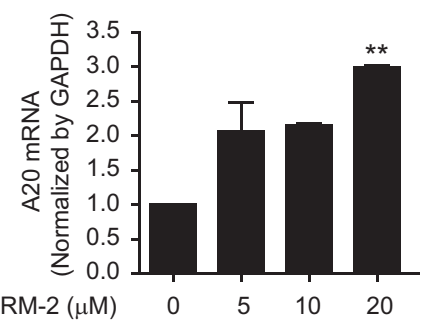

g

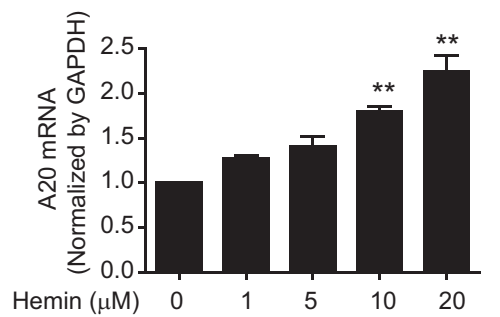

d

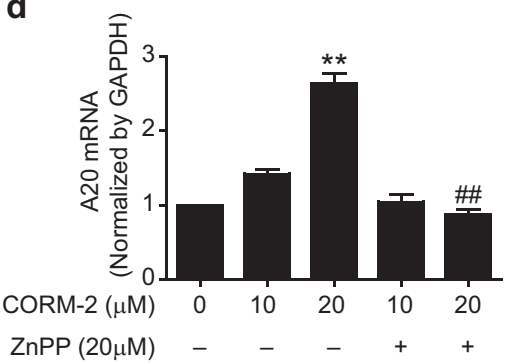

h

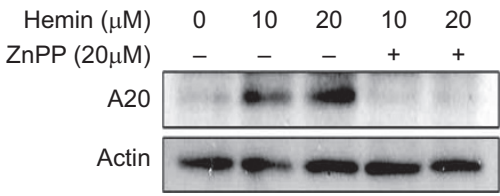

Figure 3 CORM-2 and hemin increases A20 expression via HO-1 activation in RAW264.7 macrophages. (a) RAW264.7 cells were incubated with CORM-2 $(20 \mu \mathrm{M})$ for 0, 2, 4, 8, 16 and $24 \mathrm{~h}$, and western blot analysis was performed to detect A20 expression. (b and c) Cells were treated with CORM$2(0,5,10,20$ and $40 \mu \mathrm{M})$ for 8 and $24 \mathrm{~h}$ and then, the levels of (b) A20 protein and (c) A20 mRNA were measured by western blot analysis and real-time RT-PCR analysis, respectively. (d and e) Cells were pre-treated with ZnPP $(20 \mu \mathrm{M})$ for $0.5 \mathrm{~h}$ and further incubated with CORM-2 (10 and $20 \mu \mathrm{M})$ for 8 or $24 \mathrm{~h}$. (d) The levels of A20 mRNA were analyzed at $8 \mathrm{~h}$ by real-time RT-PCR. (e) A20 protein level was carried out at $24 \mathrm{~h}$ by western blot analysis. (f) Cells were transfected with HO-1 siRNA or control siRNA (Con siRNA). Cells were treated with $20 \mu \mathrm{M} \mathrm{CORM-2} \mathrm{for} 24 \mathrm{~h}$, and cells were harvested and protein levels of HO-1 and A20 were performed by western blotting. (g) Cells were treated with hemin at various doses for $8 \mathrm{~h}$, and the levels of A2O mRNA were analyzed by real-time RT-PCR. (h) Cells were pre-treated with ZnPP ( $20 \mu \mathrm{M})$ for $0.5 \mathrm{~h}$ and hemin $(10$ and $20 \mu \mathrm{M})$ was treated for $24 \mathrm{~h}$, and then A20 protein level was analyzed by western blot analysis. The representative bands or blots are shown. Data represent mean \pm s.e.m., $* * P<0.001$ as compared with control; and ${ }^{\# \#} P<0.001$ as compared with the cells exposed only to CORM-2, respectively.

(Figrue 5e) in liver tissue and blood serum from LPS-induced endotoxemic mice. Therefore, the results from in vivo experiments suggest that $\mathrm{CO}$ and $\mathrm{HO}-1$ mediate anti-inflammatory activities through IRG1 and A20 expression in the septic mice model.

\section{DISCUSSION}

Macrophages can exert pro- or anti-inflammatory functions depending on the type of stimuli. ${ }^{31}$ Anti-microbial activity has been observed in activated peripheral macrophages and microglial cells during inflammation. ${ }^{3}$ Previously, it has been reported that $\mathrm{HO}-1$ induction through the PI3K/Akt/Nrf2 signaling pathway is associated with protection against oxidative stress. ${ }^{32,33}$ In murine cerebral endothelium, inhibition of NF- $\kappa \mathrm{B}$ and COX2 by CoPP, a HO-1 inducing compound, suggests protective functions of HO- $1 .{ }^{34}$ Mitochondrial injury is experimentally and clinically well recognized in sepsis. ${ }^{35} \mathrm{HO}-1$ activates mitochondrial biogenesis, ${ }^{36}$ and thus, may limit inflammatory damage and improve cell survival during bacterial sepsis. ${ }^{37}$

IRG1 is highly upregulated in murine macrophages and microglial cells under pro-inflammatory conditions. ${ }^{6}$ Furthermore, reduced antimicrobial activity was evident in IRG1-deficient macrophages during bacterial infection. ${ }^{38}$ IRG1 can regulate mitochondrial $\beta$-oxidation and mitochondrial ROS production. ${ }^{38}$ Mitochondrial localization of IRG $1^{6}$ is involved in mitochondrial ROS production which governs macrophage bactericidal activity, $^{38}$ and altered production of pro-inflammatory cytokines. ${ }^{39}$ In addition, IRG1 exerts anti-microbial activity on pathogens through synthesizing itaconic acid. ${ }^{40}$ Thus, IRG1 plays a crucial role in macrophage function and inflammation. ${ }^{38}$ Interestingly, HO-1 and IRG1 are both expressed during LPS tolerance and provide protection against inflammation, suggesting a possible relationship between HO-1 and IRG1. IRG1 is highly expressed during inflammation and proven to have anti-inflammatory as well as anti-microbial activity in macrophages, yet the underlying molecular mechanisms have not yet been elucidated. In this study, we demonstrate that HO-1 mediates its anti-inflammatory effects through IRG1 expression under septic conditions.

To investigate a possible interaction between $\mathrm{HO}-1$ and IRG1, we treated macrophages with $\mathrm{ZnPP}$, a selective inhibitor of HO-1 activity. ${ }^{41}$ Inhibition of HO-1 activity resulted in the inhibition of IRG1 expression that was upregulated by treatment of macrophages with CORM-2 or HO-1 inducers. Our results suggest that the stimulatory effect of CORM-2, a CO 
a

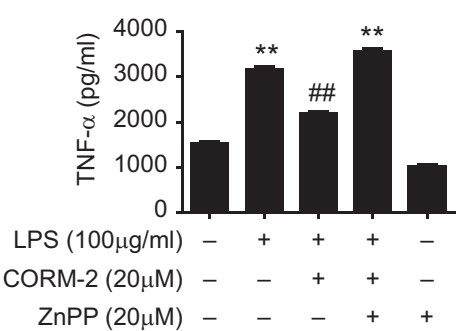

b

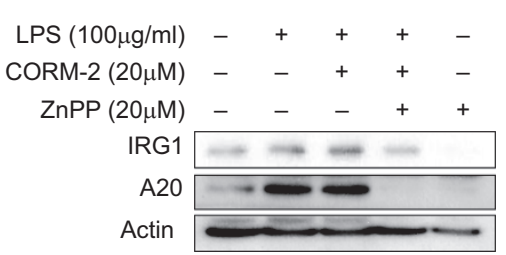

c

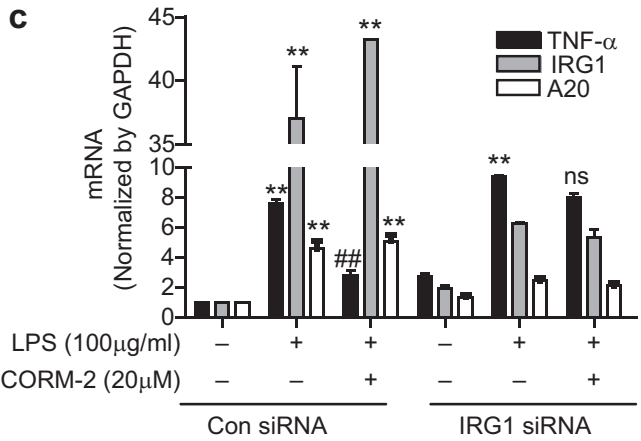

d

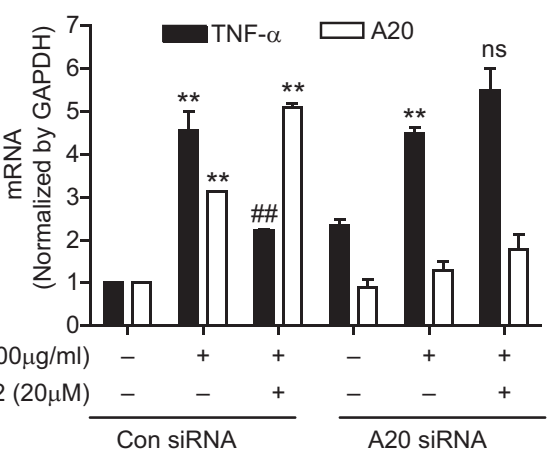

g

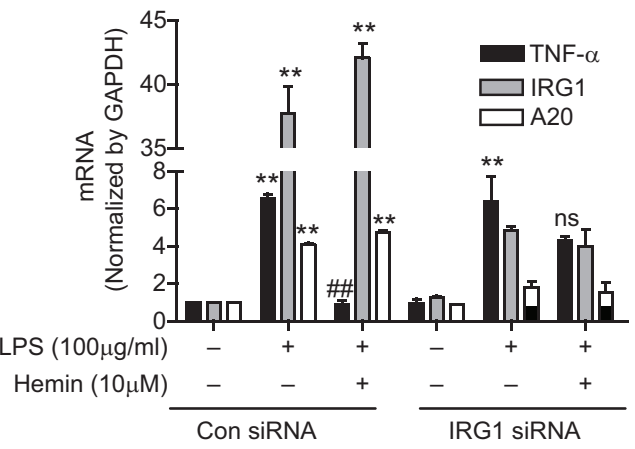

e

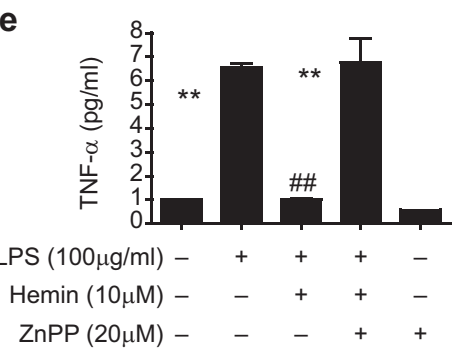

f h

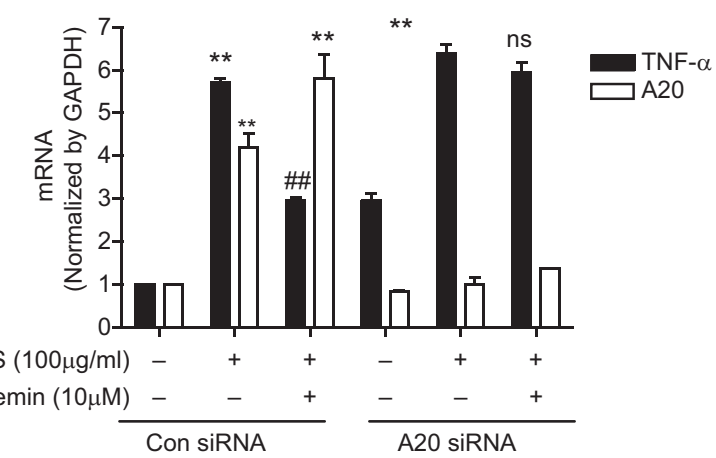

Figure 4 CORM-2/hemin-induced IRG1 decreases inflammation via A20 expression in RAW264.7 macrophages. (a and b) RAW264.7 cells were pre-treated with ZnPP ( $20 \mu \mathrm{M})$ for $0.5 \mathrm{~h}$ and then administrated with CORM-2 (20 $\mu \mathrm{M})$ for $1 \mathrm{~h}$ and further incubated with LPS (100 ng/ml) for $24 \mathrm{~h}$. (a) Cell supernatants were analyzed by ELISA to measure TNF- $\alpha$. (b) Cell lysates were subjected western blot analysis for protein level of IRG1 and A20. (c) Cells were transiently transfected with IRG1 siRNA or control siRNA (Con siRNA). After treatment with CORM-2 (20 $\mu$ M) for 1 h, the cells were stimulated with LPS (100 ng/ml) for $24 \mathrm{~h}$, and the levels of TNF- $\alpha$, A20 and IRG1 mRNA were analyzed by real-time RT-PCR. (d) Cells were transfected with A20 siRNA or control siRNA (Con siRNA). Following treatment with $20 \mu \mathrm{M}$ CORM- 2 for $1 \mathrm{~h}$, the cells were stimulated with $100 \mathrm{ng} / \mathrm{mL}$ LPS for $24 \mathrm{~h}$, the levels of TNF- $\alpha$ and A20 mRNA were analyzed by real-time RT-PCR. (e and f) Cells were pre-treated with ZnPP ( $20 \mu \mathrm{M}$ ) for $0.5 \mathrm{~h}$ and then administrated with hemin $(10 \mu \mathrm{M})$ for $1 \mathrm{~h}$ and incubated with LPS (100 ng/mL) for $24 \mathrm{~h}$. (e) Cell supernatants were subjected for ELISA to measure TNF- $\alpha$. (f) Cell lysates were subjected to western blot analysis to determine the protein level of IRG1 and A20. (g) Cells were transfected with IRG1 siRNA or control siRNA (Con siRNA). After treatment with $10 \mu \mathrm{M}$ hemin for $1 \mathrm{~h}$, the cells were stimulated with $100 \mathrm{ng} / \mathrm{ml} \mathrm{LPS}$ for $24 \mathrm{~h}$, and the levels of TNF- $\alpha$, A20 and IRG1 mRNA were analyzed by real-time RT-PCR. (h) Cells were transfected with A20 siRNA or control siRNA (Con siRNA). After treatment with $10 \mu \mathrm{M}$ hemin for $1 \mathrm{~h}$, the cells were stimulated with $100 \mathrm{ng} / \mathrm{ml}$ LPS for $24 \mathrm{~h}$, and the levels of TNF- $\alpha$ and A20 mRNA were analyzed by real-time RT-PCR. Data represent mean \pm s.e.m., $* P<0.05$ and $* * P<0.001$ as compared with control; and ${ }^{\#} P<0.05$, ${ }^{\# \#} P<0.001$ as compared with the cells exposed to only LPS (normal condition or IRG1/A20 siRNA, compared separately) and ns, non-significant as compared with only LPS (IRG siRNA or A20 siRNA).

donor, on IRG1 expression depends on the subsequent stimulation of $\mathrm{HO}$ activity, which generates $\mathrm{CO}$ and other end products. Thus, our results suggest a regulatory role for HO-1 activity in IRG1 expression. Furthermore, genetic deletion of HO- 1 in mice resulted in significant reduction of IRG1 mRNA expression, confirming regulation of IRG1 by HO- 1 . The endogenous free radical gaseous mediator $\mathrm{NO}$ can also induce $\mathrm{HO}-1$ expression in a variety of cells, including macrophages and vascular smooth muscle cells. ${ }^{26,42}$ To confirm HO-1 involvement in IRG1 expression, we used the NO donor SNAP. We found that IRG1 was significantly upregulated by SNAP, which was reversed by $\mathrm{ZnPP}$-dependent inhibition of HO-1 activity, which further supports a regulatory role of HO-1 in IRG1 expression. 
a
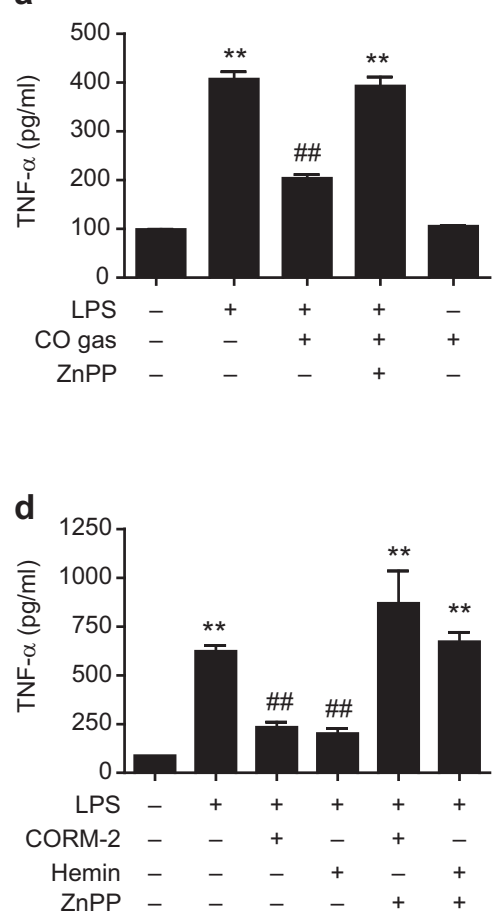

b

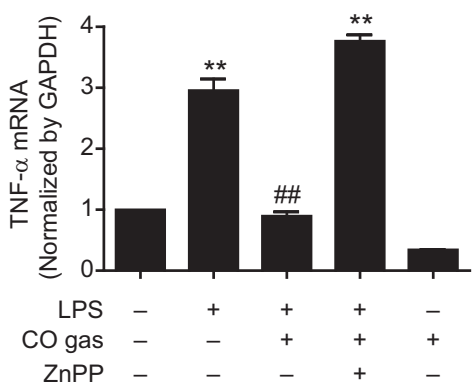

e

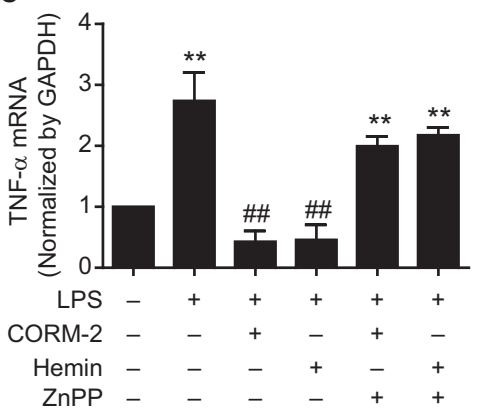

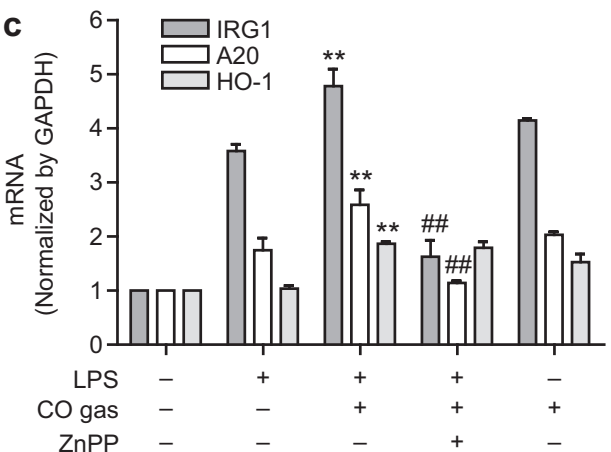

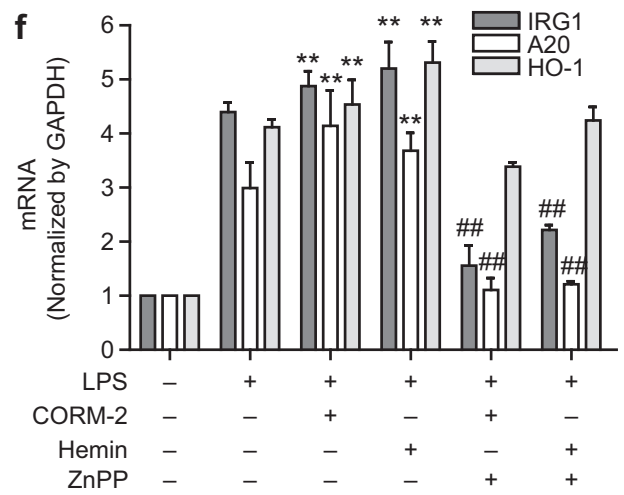

Figure 5 Inhalation of $\mathrm{CO}$ gas and administration of CORM-2 and hemin increase IRG1 and A2O expression via HO-1 expression and decrease inflammation in a sepsis mouse model in vivo. (a-c) Wild-type 7-week-old male C57BL/6 mice were inhaled with CO gas (250 ppm) for 6 days (4 h daily basis) and some of them were administrated with ZnPP (5 mg/kg; i.p.). After 6 days, the mice were administrated with LPS (12.5 mg/kg; i.p.) for $16 \mathrm{~h}$. (a) Blood serum was analyzed for the TNF- $\alpha$ level by ELISA. (b) Liver tissues were analyzed for the levels of TNF- $\alpha$ by real-time RT-PCR. (c) Liver tissues were analyzed for the levels of IRG1, A20 and HO-1 mRNA by real-time RT-PCR. (d-f) Wild-type 7-week-old male C57BL/6 mice were pre-treated with CORM-2 (30 mg/kg; i.p.), hemin (10 mg/kg; i.p.) and ZnPP (5 mg/kg; i.p.) for $2 \mathrm{~h}$ and, then, the mice were administrated with LPS (12.5 mg/kg; i.p.) for 16 h. (d) Blood serum was analyzed for the TNF- $\alpha$ level by ELISA. (e) Liver tissues were analyzed for the levels of TNF- $\alpha$ by realtime RT-PCR. (f) Liver tissues were analyzed for the levels of IRG1, A20 and HO-1 mRNA by real-time RT-PCR. Data represents mean \pm s.e.m., ${ }^{*} P<0.05$ and $* * P<0.001$ as compared with control; and ${ }^{\#} P<0.05$ and ${ }^{\# \#} P<0.001$ as compared with the cells exposed to LPS + CO/CORM-2/hemin (in case TNF- $\alpha,{ }^{\# \#} P<0.001$ as compared with the cells exposed to only LPS).

A20 was at first identified as a TNF-inducible gene in HUVECs. ${ }^{43}$ A20 protein can protect cells from TNF- $\alpha$-induced cytotoxicity. ${ }^{28}$ The significance of A20 in downregulating NF$\kappa \mathrm{B}$ and inflammation was found in A20-knockdown mice that underwent severe and multiorgan inflammation and cachexia just after birth. ${ }^{44}$ Furthermore, TNF- $\alpha$-induced apoptosis and NF- $\kappa \mathrm{B}$ activation were inhibited by A20 over-expression. ${ }^{45}$ Thus, it is clear that A20 is involved in the inhibition of NF$\mathrm{\kappa B}$ signaling and inflammation. Recently, IRG1 has been reported to promote endotoxin tolerance by increasing A20 expression in macrophages through ROS production. ${ }^{11}$ Therefore, to examine the anti-inflammatory, interactive and mechanistic effects of both $\mathrm{CO}$ treatment and HO-1 induction on IRG1 and A20 expression, we treated macrophages with CORM-2 and hemin. Based on our observations that CORM-2 treatment and $\mathrm{HO}-1$ induction by hemin significantly increased IRG1 and A20 expression, which were reversed by ZnPP, we conclude that the HO-1/CO system increases both IRG1 and A20 expression. These results prompted us to examine whether $\mathrm{CO}$ treatment and HO-1 induction would mediate anti-inflammatory effects via IRG1 and A20 expression. To support the anti-inflammatory effects of HO-1/CO -mediated IRG1 and A20, we incubated macrophages with $\mathrm{CO}$ or hemin in the absence and presence of ZnPP, followed by LPS stimulation. Interestingly, $\mathrm{ZnPP}$ significantly reversed $\mathrm{HO}-1 / \mathrm{CO}-$ mediated inhibition of TNF- $\alpha$ expression, along with a decrease in IRG1 and A20 expression. Our findings thus suggest that $\mathrm{CO}$ and $\mathrm{HO}-$ 1 inhibit inflammation by increasing IRG1 and A20 expression. Furthermore our results were confirmed by observations that siRNA targeting IRG1 and A20 reversed the inhibitory effect of HO-1/CO on LPS-stimulated TNF- $\alpha$ production.

Sepsis, a systemic inflammatory response, results from excessive stimulation of the host immune system by pathogen components to produce various pro-inflammatory cytokines, and the excessive secretion of these cytokines cause systemic inflammation leading to the lethal multiple organ damage. ${ }^{46} \mathrm{In}$ our study, we demonstrated that $\mathrm{CO}$ treatment and HO-1 induction significantly increased IRG1 and A20 expression and decreased TNF- $\alpha$ production in an LPS-stimulated sepsis mice model. In addition, the effect of CO/HO-1 on TNF- $\alpha$ production was significantly reversed with intraperitoneal administration of $\mathrm{ZnPP}$, confirming a role for $\mathrm{HO}-1$ activity. 


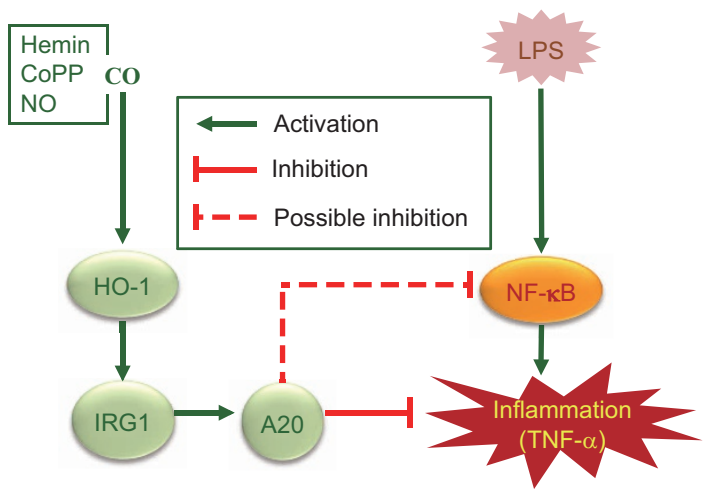

Figure 6 Regulation of LPS-induced inflammation by CO in RAW264.7 macrophages and in mice. $\mathrm{CO}$, in addition to $\mathrm{HO}-1$ inducers including hemin, CoPP and NO, induces HO-1 expression that in turn induces IRG1 and A20 expression, thereby regulating LPS-induced inflammation.

In summary, we have identified that $\mathrm{CO}$ treatment with exogenous donor compounds and chemically induced HO-1 induction can regulate IRG1 and A20 expression, thereby inhibiting inflammation in vitro and in a mouse model of sepsis, as illustrated in Fig. 6. This study identifies a novel $\mathrm{CO} / \mathrm{HO}-$ 1/IRG1/A20 signaling pathway responsible for the inhibition of LPS-driven inflammation and potentially provides the rationale for novel therapeutic strategies for the treatment of inflammatory diseases.

\section{CONFLICT OF INTEREST}

There is no conflict of interest.

\section{ACKNOWLEDGEMENTS}

This study was supported by the Bio \& Medical Technology Development Program of the National Research Foundation (NRF) funded by the Ministry of Science, ICT \& Future Planning (2012M3A9C3048687) and NRF-2014R1A6A1030318.

Supplementary Information accompanies the paper on Cellular \& Molecular Immunology's website. (http://www.nature.com/cmi).

1 Hotchkiss RS, Opal S. Immunotherapy for sepsis-a new approach against an ancient foe. N Engl J Med 2010; 363: 87-89.

2 Riedemann NC, Guo RF, Ward PA. Novel strategies for the treatment of sepsis. Nat Med 2003; 9: 517-524.

3 David S, Kroner A. Repertoire of microglial and macrophage responses after spinal cord injury. Nat Rev Neurosci 2011; 12: 388-399.

4 Lee CG, Jenkins NA, Gilbert DJ, Copeland NG, O'Brien WE. Cloning and analysis of gene regulation of a novel LPS-inducible CDNA. Immunogenetics 1995; 41: 263-270.

5 Tangsudjai S, Pudla M, Limposuwan K, Woods DE, Sirisinha S, Utaisincharoen P. Involvement of the MyD88-independent pathway in controlling the intracellular fate of Burkholderia pseudomallei infection in the mouse macrophage cell line RAW 264.7. Microbiol Immunol 2010; 54: 282-290.

6 Degrandi D, Hoffmann R, Beuter-Gunia C, Pfeffer K. The proinflammatory cytokine-induced IRG1 protein associates with mitochondria. J Interferon Cytokine Res 2009; 29: 55-67.

7 Matulova M, Rajova J, Vlasatikova L, Volf J, Stepanova H, Havlickova $\mathrm{H}$ et al. Characterization of chicken spleen transcriptome after infection with Salmonella enterica serovar Enteritidis. PLoS One 2012; 7: e48101.

8 Cheon YP, Xu X, Bagchi MK, Bagchi IC. Immune-responsive gene 1 is a novel target of progesterone receptor and plays a critical role during implantation in the mouse. Endocrinology 2003; 144: 5623-5630.

9 Mor G, Cardenas I, Abrahams V, Guller S. Inflammation and pregnancy: the role of the immune system at the implantation site. Ann NY Acad Sci 2011; 1221: 80-87.

10 Li H, Gang Z, Yuling H, Luokun X, Jie X, Hao L et al. Different neurotropic pathogens elicit neurotoxic CCR9- or neurosupportive CXCR3-expressing microglia. J Immunol 2006; 177: 3644-3656.

11 Li Y, Zhang P, Wang C, Han C, Meng J, Liu X et al. Immune responsive gene 1 (IRG1) promotes endotoxin tolerance by increasing A20 expression in macrophages through reactive oxygen species. $J$ Biol Chem 2013; 288: 16225-16234.

12 Maines MD. The heme oxygenase system: a regulator of second messenger gases. Annu Rev Pharmacol Toxicol 1997; 37: 517-554.

13 Ryter SW, Alam J, Choi AM. Heme oxygenase-1/carbon monoxide: from basic science to therapeutic applications. Physiol Rev 2006; 86: 583-650.

14 Devesa I, Ferrandiz ML, Terencio MC, Joosten LA, van den Berg WB, Alcaraz MJ. Influence of heme oxygenase 1 modulation on the progression of murine collagen-induced arthritis. Arthritis Rheum 2005; 52: 3230-3238.

15 Hegazi RA, Rao KN, Mayle A, Sepulveda AR, Otterbein LE, Plevy SE. Carbon monoxide ameliorates chronic murine colitis through a heme oxygenase 1-dependent pathway. J Expe Med 2005; 202: 1703-1713.

16 Lee TS, Chau LY. Heme oxygenase-1 mediates the anti-inflammatory effect of interleukin-10 in mice. Nat Med 2002; 8: 240-246.

17 Mandal P, Park PH, McMullen MR, Pratt BT, Nagy LE. The antiinflammatory effects of adiponectin are mediated via a heme oxygenase-1-dependent pathway in rat Kupffer cells. Hepatology 2010; 51: 1420-1429.

18 Koch A, Boehm O, Zacharowski PA, Loer SA, Weimann J, Rensing H et al. Inducible nitric oxide synthase and heme oxygenase- 1 in the lung during lipopolysaccharide tolerance and cross tolerance. Crit Care Med 2007; 35: 2775-2784.

19 Soriano RN, Ravanelli MI, Batalhao ME, Carnio EC, Branco LG. Glucocorticoids downregulate systemic nitric oxide synthesis and counteract overexpression of hepatic heme oxygenase-1 during endotoxin tolerance. Can J Physiol Pharmacol 2013; 91: 861-865.

20 Motterlini R, Clark JE, Foresti R, Sarathchandra P, Mann BE, Green CJ. Carbon monoxide-releasing molecules: characterization of biochemical and vascular activities. Circ Res 2002; 90: E17-E24.

21 Ewing P, Hildebrandt GC, Planke S, Andreesen R, Holler E, Gerbitz A. Cobalt protoporphyrine IX-mediated heme oxygenase-I induction alters the inflammatory cytokine response, but not antigen presentation after experimental allogeneic bone marrow transplantation. Int J Mol Med 2007; 20: 301-308.

22 Anderson KE, Collins S. Open-label study of hemin for acute porphyria: clinical practice implications. Am J Med 2006; 119: 801.e819-801.e 824.

23 Devadas K, Dhawan S. Hemin activation ameliorates HIV-1 infection via heme oxygenase-1 induction. J Immunol 2006; 176: 4252-4257.

24 Paxinou E, Weisse M, Chen Q, Souza JM, Hertkorn C, Selak M et al. Dynamic regulation of metabolism and respiration by endogenously produced nitric oxide protects against oxidative stress. Proc Natl Acad Sci USA 2001; 98: 11575-11580.

25 Beltran B, Mathur A, Duchen MR, Erusalimsky JD, Moncada S. The effect of nitric oxide on cell respiration: a key to understanding its role in cell survival or death. Proc Natl Acad Sci USA 2000; 97: 14602-14607.

26 Hartsfield CL, Alam J, Cook JL, Choi AM. Regulation of heme oxygenase-1 gene expression in vascular smooth muscle cells by nitric oxide. Am J Physiol 1997; 273(5 Pt 1): L980-L988.

27 Sun SC. Deubiquitylation and regulation of the immune response. Nat Rev Immunol 2008; 8: 501-511.

28 Opipari AW Jr, Hu HM, Yabkowitz R, Dixit VM. The A20 zinc finger protein protects cells from tumor necrosis factor cytotoxicity. J Biol Chem 1992; 267: 12424-12427. 
29 Otterbein L, Sylvester SL, Choi AM. Hemoglobin provides protection against lethal endotoxemia in rats: the role of heme oxygenase-1. Am J Respir Cell Mol Biol 1995; 13: 595-601.

$30 \mathrm{Yu}$ JB, Yao SL. Protective effects of hemin pretreatment combined with ulinastatin on septic shock in rats. Chin Med J 2008; 121: 4955.

31 Martinez FO, Sica A, Mantovani A, Locati M. Macrophage activation and polarization. Front Biosci 2008; 13: 453-461.

32 Park MK, Kang YJ, Ha YM, Jeong JJ, Kim HJ, Seo HG et al. EP2 receptor activation by prostaglandin E2 leads to induction of $\mathrm{HO}-1$ via PKA and PI3K pathways in $\mathrm{C} 6$ cells. Biochem Biophys Res Commun 2009; 379: 1043-1047.

33 Tsoyi K, Jang HJ, Kim JW, Chang HK, Lee YS, Pae HO et al. Stimulation of alpha7 nicotinic acetylcholine receptor by nicotine attenuates inflammatory response in macrophages and improves survival in experimental model of sepsis through heme oxygenase-1 induction. Antioxid Redox Signal 2011; 14: 2057-2070.

34 Shih RH, Yang CM. Induction of heme oxygenase- 1 attenuates lipopolysaccharide-induced cyclooxygenase-2 expression in mouse brain endothelial cells. J Neuroinflamm 2010; 7: 86.

35 Kantrow SP, Taylor DE, Carraway MS, Piantadosi CA. Oxidative metabolism in rat hepatocytes and mitochondria during sepsis. Arch Biochem Biophys 1997; 345: 278-288.

36 Piantadosi CA, Carraway MS, Babiker A, Suliman HB. Heme oxygenase-1 regulates cardiac mitochondrial biogenesis via Nrf2mediated transcriptional control of nuclear respiratory factor-1. Circ Res 2008; 103: 1232-1240.

37 Piantadosi CA, Withers CM, Bartz RR, MacGarvey NC, Fu P, Sweeney TE et al. Heme oxygenase- 1 couples activation of mitochondrial biogenesis to anti-inflammatory cytokine expression. J Biol Chem 2011; 286: 16374-16385.

38 Hall CJ, Boyle RH, Astin JW, Flores MV, Oehlers SH, Sanderson LE et al. Immunoresponsive gene 1 augments bactericidal activity of macrophage-lineage cells by regulating beta-oxidation-dependent mitochondrial ROS production. Cell Metab 2013; 18: 265-278.
39 Naik E, Dixit VM. Mitochondrial reactive oxygen species drive proinflammatory cytokine production. J Exp Med 2011; 208: 417-420.

40 Michelucci A, Cordes T, Ghelfi J, Pailot A, Reiling N, Goldmann 0 et al. Immune-responsive gene 1 protein links metabolism to immunity by catalyzing itaconic acid production. Proc Natl Acad Sci USA 2013; 110: 7820-7825.

41 Yang G, Nguyen X, Ou J, Rekulapelli P, Stevenson DK, Dennery PA. Unique effects of zinc protoporphyrin on $\mathrm{HO}-1$ induction and apoptosis. Blood 2001; 97: 1306-1313.

42 Hara E, Takahashi K, Takeda K, Nakayama M, Yoshizawa M, Fujita H et al. Induction of heme oxygenase- 1 as a response in sensing the signals evoked by distinct nitric oxide donors. Biochem Pharmacol 1999; 58: 227-236.

43 Opipari AW Jr, Boguski MS, Dixit VM. The A20 cDNA induced by tumor necrosis factor alpha encodes a novel type of zinc finger protein. J Biol Chem 1990; 265: 14705-14708.

44 Lee EG, Boone DL, Chai S, Libby SL, Chien M, Lodolce JP et al. Failure to regulate TNF-induced NF-kappaB and cell death responses in A20deficient mice. Science 2000; 289: 2350-2354.

45 Beyaert R, Heyninck K, van Huffel S. A20 and A20-binding proteins as cellular inhibitors of nuclear factor-kappa B-dependent gene expression and apoptosis. Biochem Pharmacol 2000; 60: 11431151.

46 Oberholzer A, Oberholzer C, Moldawer LL. Sepsis syndromes: understanding the role of innate and acquired immunity. Shock 2001; 16: 83-96.

\section{(c) (1) $(9)$ This work is licensed under a Creative Commons} Attribution-NonCommercial-NoDerivs 3.0 Unported License. The images or other third party material in this article are included in the article's Creative Commons license, unless indicated otherwise in the credit line; if the material is not included under the Creative Commons license, users will need to obtain permission from the license holder to reproduce the material. To view a copy of this license, visit http://creativecommons.org/licenses/by-nc-nd/3.0/ 